\title{
Pengaruh Kuat Arus Las Terhadap Sifat Mekanis dan Struktur Mikro Sambungan Las Besi Tuang Kelabu menggunakan Elektroda Nikel dengan Proses Pengelasan SMAW
}

\author{
Daryono $^{1}$, Topan Prihantoro ${ }^{2}$, Ady Setiawan ${ }^{3}$ \\ 1,2,3 Jurusan Teknik Mesin, Program Studi Teknologi Mesin \\ PSDKU Politeknik Negeri Pontianak Kampus Sanggau \\ Email: ${ }^{1}$ daryono.ref@gmail.com, ${ }^{2}$ topan.prihantoro@gmail.com, ${ }^{3}$ adys62409@gmail.com
}

\begin{abstract}
ABSTRAK
Penelitian ini bertujuan untuk mengetahui pengaruh arus pengelasan terhadap sifat mekanik dan struktur mikro pada sambungan las besi cor kelabu menggunakan elektroda nikel dengan proses pengelasan SMAW. Memtode penelitian yang digunakan adalah studi eksperimen, dimulai dari mempersiapkan benda kerja, proses pengelasan, pembuatan spesimen uji, dan pengujian spesimen las. Bahan yang disambung yaitu logam besi cor dengan bentuk sambungan butt joint kampuh V terbuka sudut $60^{\circ}$. Proses las yang digunakan adalah SMAW dengan arus 80 Ampere, 85 Ampere dan 90 Ampere. Bahan tambah yang digunakan adalah elektroda CIN 2 jenis ENiFe-Cl diameter 2,6 mm. Pengujian kekerasan dilakukan dengan metode Vickers dan pengujian struktur mikro menggunakan mikroskop metalurgi. Hasil penelitian menunjukkan bahwa nilai kekerasan maksimum logam induk terjadi pada kuat arus pengelasan 85 ampere yaitu sebesar 192,17 VHN, kemudian nilai kekerasan maksimum daerah HAZ terjadi pada kuat arus pengelasan 85 ampere yaitu sebesar 203,46 VHN sedangkan nilai kekerasan maksimum logam lasan (weld metal) terjadi pada kuat arus pengelasan 90 ampere yaitu sebesar 211,18 VHN. Dari hasil pengamatan struktur mikro terlihat matriks yang terbentuk pada logam induk berupa perlit dengan grafit berupa flake (serpih). Struktur mikro yang terbentuk pada daerah HAZ berupa struktur martensit. Sedangkan struktur mikro pada weld metal terdiri dari matriks austenite dengan persebaran partikel grafit yang merata.
\end{abstract}

Kata Kunci : arus pengelasan, besi cor kelabu, elektroda

\section{ABSTRACT}

This study aims to determine the effect of welding current on the mechanical properties and microstructure of gray cast iron welding joints using nickel electrodes with the SMAW welding process. The research method used was experimental study, starting with preparing the workpiece, welding process, making test specimens and testing the weld specimens. The material to be joined is gray cast iron metal with a butt joint of a $60^{\circ}$ open seam V open angle. The welding process used uses SMAW with a current of 80 Amperes, 85 Amperes and 90 Amperes. The added material used was an ENiFe-Cl type CIN 2 electrode with a diameter of $2.6 \mathrm{~mm}$. Hardness testing was carried out using the Vickers method and microstructure testing using an optical microscope. The results showed that the maximum hardness value of the parent metal occurred at the welding current strength of 85 Amperes, which was $192.17 \mathrm{VHN}$, then the maximum hardness value of the HAZ area occurred at the welding current strength of 85 Amperes, which was 203.46 VHN, while the maximum hardness value of the weld metal was 203.46 VHN. metal) occurred at a welding current of 90 Amperes, which was 211.18 $V H N$. The results of the microstructure observation showed that the matrix formed on the parent metal was pearlite with graphite in the form of flakes. The micro structure formed in the HAZ area was a martensite structure. Meanwhile, the microstructure of weld metal consists of an austenite matrix with an even distribution of graphite particles.

Keywords: welding current, gray cast iron, electrodes 


\section{Pendahuluan}

logam merupakan material yang sangat di perlukan bagi khususnya industri manufaktur,dan sebagai produk alat transportasi udara, darat, dan air dan sebagai konstruki pembangunan jalan. dalam rekayasa dan reparasi logam.

Besi cor banyak sekali di temukan pada mesin-mesin produksi, dan mesin otomotif salah satunya bentuk blok head slinder dan lain sebagainya.

Peralatan atau mesin yang terbuat dari besi cor terkadang mengalami kerusakan atau dilakukan modifikasi guna meningkatkan performa alat/mesin. Salah satu proses untuk menunjang kegiatan perawatan dan perbaikan atau modifikasi yaitu dengan proses pengelasan. SMAW ini merupakan Pengelasan yang digunakan dengan elektroda nikel.

Sifat mampu las yang rendah pada besi cor sehingga perlu perlakuan pengelasan yang benar dan tepat. banyak terjadi kegagalan dalam pengelasan adanya keretakan dengan faktor penyebabnya adalah parameter-parameter salah satunya besar kecilnya arus yang di gunakan pada pengelasan besi cor. kuat arus merupakan salah satu faktor pengaruh dari sifat mekanik halnya kekuatan tarik , kekuatan tarik, kekerasan, hasil dari pengelasan. Maka dari itu perlu dilakukan percobaan pengelasan besi cor

Dengan berbagai variasi kuat arus pengelasan guna mengetahui sifat mekanis dan struktur mikro bahan setelah dilakukan pengelasan.

Besi cor kelabu pada umumnya banyak di gunakan dengan beberapa sifat mekanis yang menguntungkann yang diantaranya adalah : mudah di cetak dengan proses penuangan dengan bentuk geometri yang rumit dan biaya relatif murah dibandingkan dengan besi cor yang lain, tahan aus atau gesekan, faktor redam yang tinggi dan kekuatan tekan yang tinggi. Namun besi cor kelabu juga memiliki beberapa besi cor antaranya: Sifatnya getas, ductility rendah.[1]

Pengelasan matrial besi tuang Memanfaatkan Elektroda Nikel pada permukaan hasil lasan baik karena tidak adanya indikasi crack/retak dan porositas yang diuji dengan dye penetrant. dengan struktur mikro berupa perlit dengan grafit berupa flake(serpih) yang tipis dan panjang Struktur mikro pada PMZ terbentuk eutektik ledeburit dan pada HAZ terbentuk struktur martensit. Sedangkan struktur mikro pada weld metal terdiri dari matriks austenit dengan persebaran partikel grafit yang merata.[2]

Sambungan las SMAW baja $516 \mathrm{gr}$, mengetahui pengaruh kuat arus dan sifat mekanis, metode yang digunakan adalah dengan melakukan Pengelasan bahwa nilai ketangguhan dan kekuatan tarik las optimum dicapai pada logam las dengan kuat arus 100 Ampere yaitu masing-masing yaitu $74 \mathrm{~J}$ dan $550 \mathrm{MPa}$. Mikro stuktur pada daerah las didominasi oleh struktur acicular ferrite.

Pengelasan menggunakan elektorda dan variasi arus pengaruh sifat fisik dan mekanik, dengan pengelasan SMAW menggunakan elektroda E7018, E6013, E7016 dan dengan arus 130A ,110A ,70A, dan pada kecepatan konstan. data yang di amati yakni sifat mekanis,dan strukktur mikro dan kekerasan. adanya pengaruh terhadap karateristik makro, struktur mikro, distribusi kekerasan dan kekuatan tariknya. [3]

Kekerasan baja merupakan resistensi terhadap lekukan permanen; dengan demikian, baja lebih keras dari pada aluminium, dan aluminium lebih keras dari timbal. [4]

Ring piston yang di gunakan sebagai kawat tambah pengelasan asitelin, dengan nilai kekuatan tarik 160 $\mathrm{N} / \mathrm{mm}^{2}$. Struktur daerah sambungan membentuk daerah lasan dan daerah HAZ. Terjadi perubahan struktur mikro daerah lasan HAZ dan daerah HAZ. maka didapat nilai kekerasan hingga mencapai 350 VHN. Sedangkan kekerasan pada daerah lasan sekitar logam induk 200 VHN, 150 VHN.[5]

Pengaruh penyusun lapisan fluks berbasis $\mathrm{CaO}-\mathrm{CaF}_{2}-$ $\mathrm{SiO}_{2}-\mathrm{Al}_{2} \mathrm{O}_{3}$ pada elektroda berbasis nikel terhadap kimia pengelasan aplikasi pembangkit listrik. diamati menggunakan penguji kekerasan mikro Vicker. Analisis regresi diterapkan untuk mengembangkan hubungan antara kimia las dan konstituen fluks. Hasil yang diperoleh dari analisis regresi kemudian dioptimalkan untuk memilih komposisi lapisan elektroda yang paling sesuai dengan keinginan yang lebih tinggi.[6]

Pengelasan Busur Logam Terlindung (SMAW) dilakukan pada lembaran baja tahan karat Pengukuran kekerasan mikro menunjukkan bahwa kekerasan manik las meningkat karena pendinginan yang cepat dan siklus termal selama prosedur pengelasan. Sifat mekanik yang diukur dan analisis profil rekahan menunjukkan bahwa kedua bahan tersebut ulet tetapi keuletannya kurang terlihat pada logam las.[7]

Baja tahan karat bebas nikel dalam aplikasi pertahanan tank tempur sebagai gantinya baja lapis yang sifat mekanik yang baik dan ketahan korosi yang lebih baik.[8]

Bahan habis pakai las baja tahan karat Austenitik (ASS) dan baja nikel tinggi (HNS) digunakan untuk pengelasan baja Q\&T, karena memiliki kelarutan yang lebih tinggi untuk hidrogen dalam fase austenitik, untuk menghindari retak akibat hidrogen (HIC) tetapi harganya sangat mahal.[9] Selain baja tahan karat ini 
didemonstrasikan untuk meningkatkan ketangguhan takik pada suhu cair dan untuk sebagai bejana bertekanan las yang kokoh pada suhu $196^{\circ} \mathrm{C}$. [10]

Tujuan dari penelitian untuk mengetahui pengaruh kuat arus pengelasan besi tuang kelabu, proses pengelasan SMAW terhadap sifat mekanis dan struktur mikro nilai kekerasan dan sebagai pengembangan ilmu pengetahuan dan teknologi dalam bidang pengelasan, terutama pengelasan besi cor.

\section{Metodologi Penelitian}

Eksperimen dengan metode eksperimen ,uji kekerasan dan struktur mikro bahan pada sambungan las dengan variasi kuat arus pengelasan. Penelitian eksperimen merupakan metode inti dari model penelitian yang menggunakan pendekatan kuantitatif. Selain itu melakukan studi literatur untuk mencari referensi dan mempelajari tentang proses pengelasan besi besi cor dan cara-cara pengujian hasil pengelasan. Bahan dan Peralatan Eksperimen

\subsection{Bahan}

Dalam penelitian ini material yang digunakan adalah sebagai berikut :

a. Besi cor kelabu ( Grey Cast Iron )

b. Elektroda CIN 2

c. Ampelas, autosol dan etsha

\subsection{Alat}

Adapun peralatan yang digunakan pada penelitian ini adalah sebagai berikut :

a. Mesin Las, mesin gerinda, mesin milling dan mesin poles

b. Alat Uji Mikro Hardness Tester

c. Mikroskop optik

d. Alat ukur

\subsection{Waktu dan Tempat Penelitian}

Penelitian dilaksanakan di Laboratorium Jurusan Teknik Mesin Politeknik Negeri Pontianak

\subsection{Tahapan Penelitian}

Bahan yang digunakan dalam penelitian ini adalah jenis besi cor kelabu (grey cast iron) yang berbentuk kepingan dengan ukuran tebal $11 \mathrm{~mm}$ lebar $50 \mathrm{~mm}$ dan panjang $100 \mathrm{~mm}$ yang diambil dari bahan pully.

a. Tahap Persiapan Benda Uji Las

- Benda yang akan dilas dilakukan proses pemotongan kemudian dilakukan proses permesinan milling untuk meratakan permukaan.

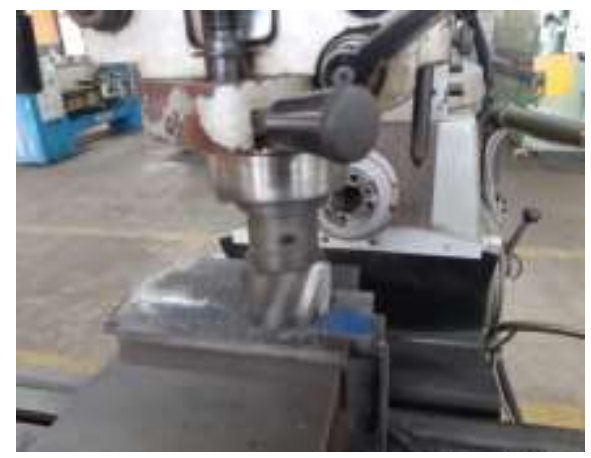

a

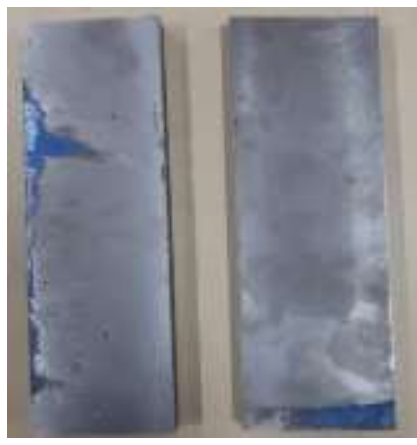

b

Gambar 1. Proses Persiapan Benda Uji Las

- Tahap berikutnya benda kerja yang telah diratakan dibuat alur kampuh bentuk $\mathrm{V}$ dengan menggunakan mesin gerinda tangan. Masingmasing sisi dari kedua benda kerja yang akan dilas digerinda membentuk sudut kemiringan $30^{\circ}$. Kemudian apabila kedua benda yang telah digerinda dengan sudut $30^{\circ}$ tersebut digabungkan maka akan terbentuk kampuh $\mathrm{V}$ terbuka dengan sudut $60^{\circ}$.

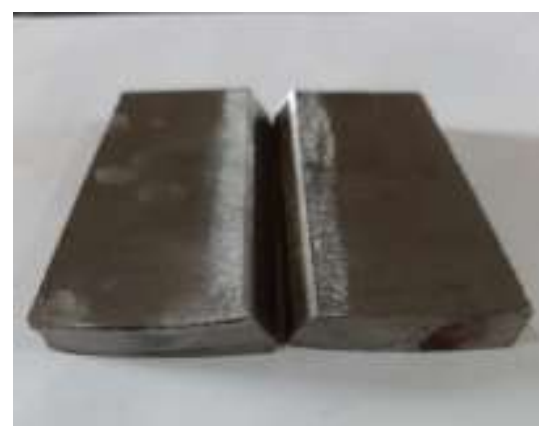

Gambar 2. Bentuk Kampuh V Benda Uji Las

b. Tahap Pengelasan

- Selanjutnya dilakukan proses pengelasan menggunakan las SMAW dengan posisi pengelasan dibawah tangan ( down hand). Elektroda yang digunakan adalah jenis CIN 2 dengan diameter 2,6 $\mathrm{mm}$ dan besar arus yang digunakan adalah $80-90 \mathrm{~A}$. 
- Setelah dilakukan proses pengelasan dilanjutkan dengan pendinginan perlahan secara alami tanpa perlakuan.

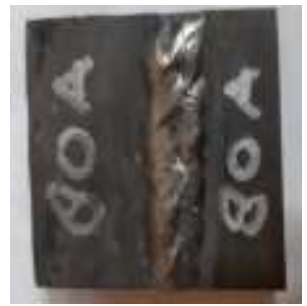

a

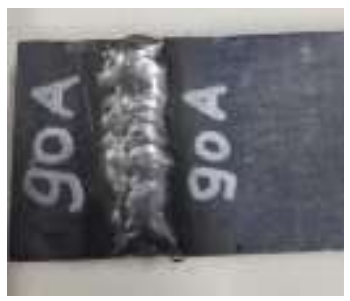

$\mathrm{b}$

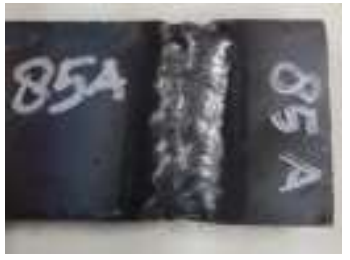

c

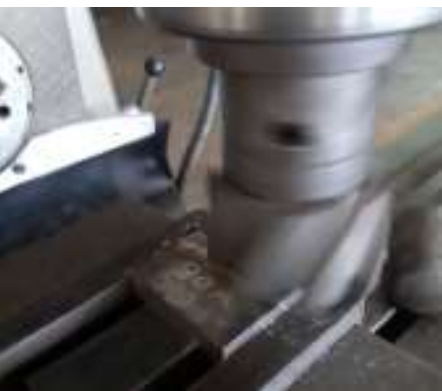

b

Gambar 4. Pembuatan Spesimen Untuk Pengujian Kekerasan dan Struktur Mikro

- Setelah proses penyiapan specimen telah selesai, selanjutnya dilakukan pengujian kekerasan Vickers dan struktur mikro pada daerah logam lasan, HAZ dan logam induk.

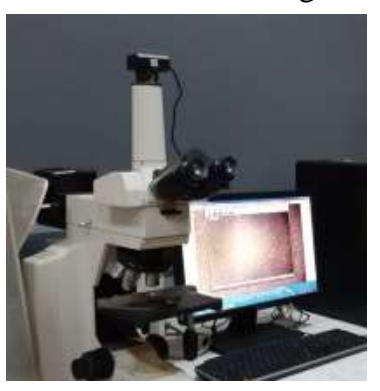

a

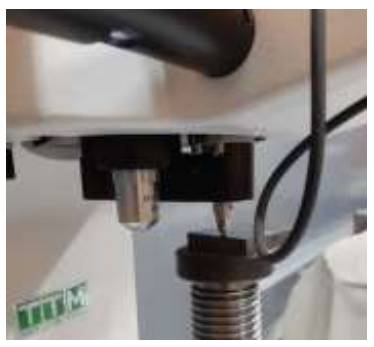

b

Gambar 5. Proses Pengujian Kekerasan dan Pengamatan Struktur Mikro

\section{Hasil}

Berikut ini data hasil penelitian eksperimen yang telah dilakukan hasil pengujian kekerasan dengan metode Vickers, seperti yang terlihat pada tabel berikut ini. 
Tabel 1. Data Hasil Pengujian Kekerasan Metode Vickers

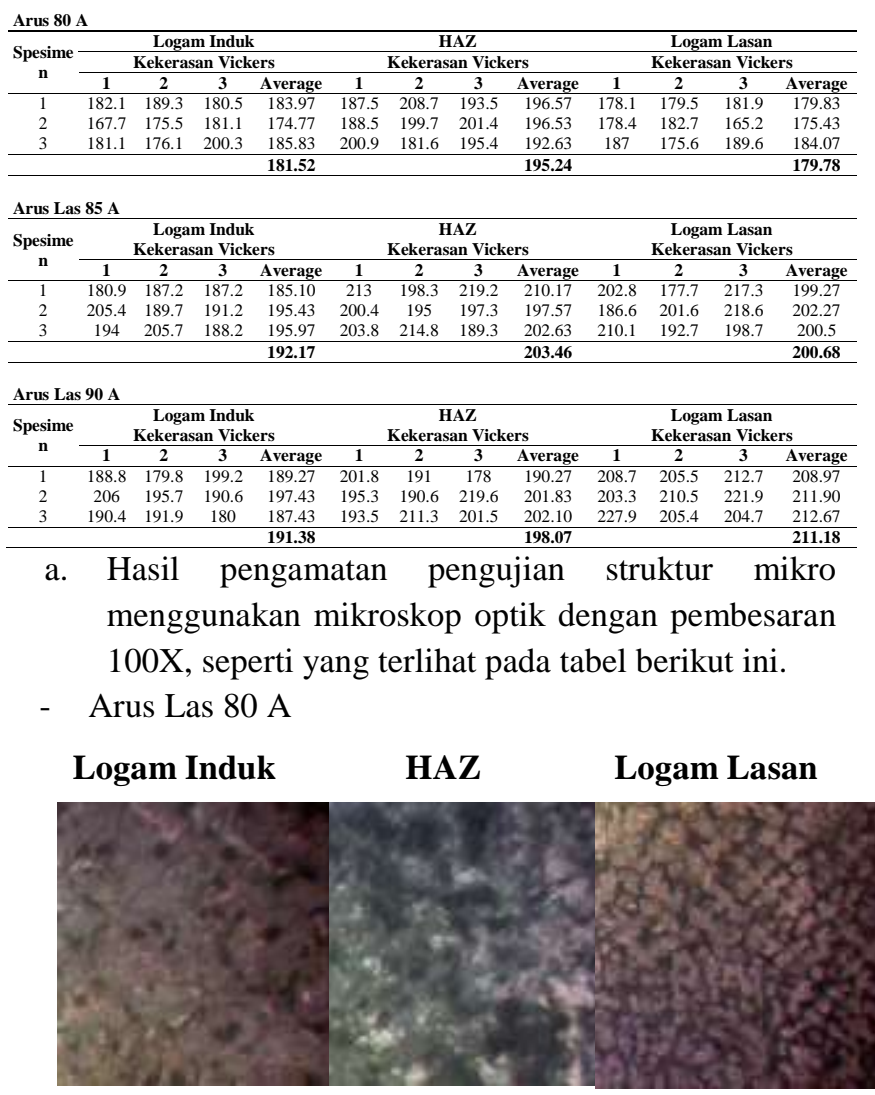

Gambar 6. Foto Struktur Mikro Hasil Pengelasan dengan Arus $80 \mathrm{~A}$

- Arus Las 85 A

Logam Induk

HAZ

Logam Lasan
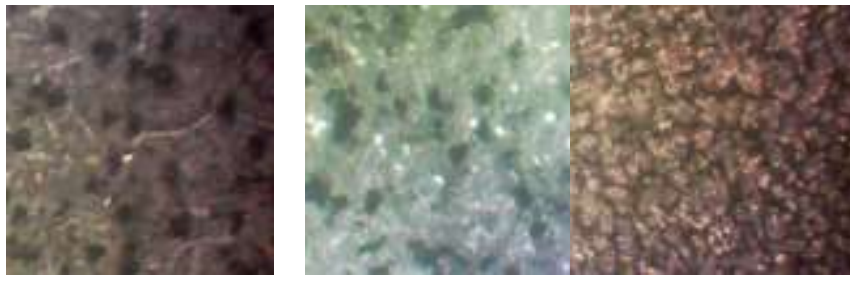

Gambar 7. Foto Struktur Mikro Hasil

Pengelasan dengan Arus 85 A

- Arus Las $90 \mathrm{~A}$

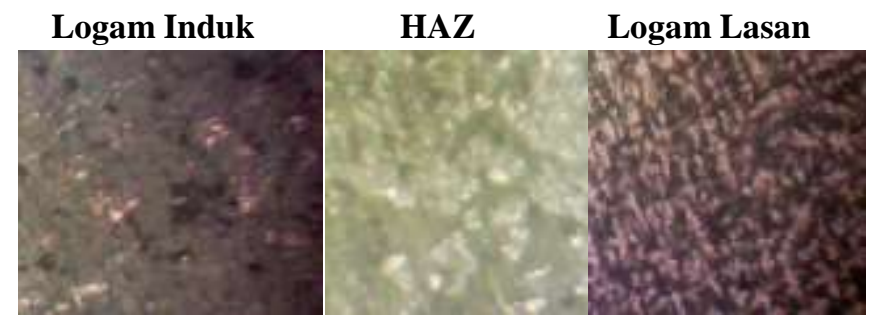

Gambar 8. Foto Struktur Mikro Hasil

Pengelasan dengan Arus 90 A

\section{Pembahasan}

\subsection{Pembahasan Uji Kekerasan}

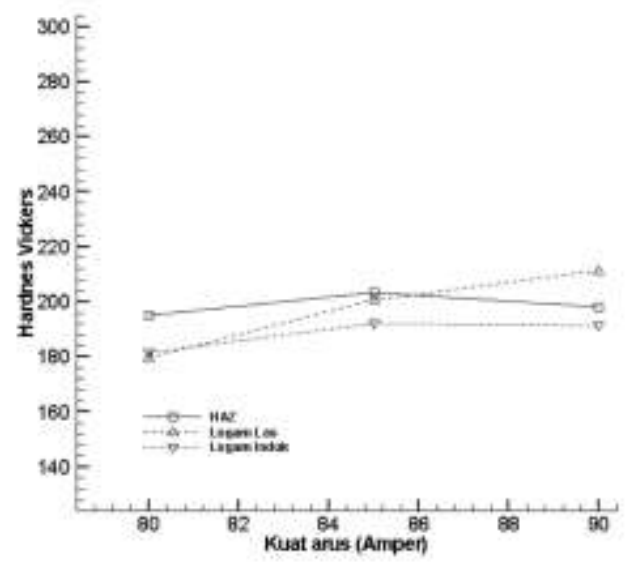

Gambar 9. Grafik nilai rata-rata kekerasan vickers pada logam induk untuk pengelasan dengan arus

\section{$80 \mathrm{~A}, 85 \mathrm{~A}$ dan $90 \mathrm{~A}$}

Grafik logam induk memperlihatkan hasil uji kekerasan besi cor kelabu pada daerah logam induk setelah mengalami proses pengelasan dengan 3 variasi arus pengelasan. Secara berurutan diperoleh nilai kekerasan logam induk pada arus 80 Amper sebesar 181,52 VHN, pada arus 85 Amper sebesar 192,17 VHN dan pada arus 90 Amper sebesar 191,38 VHN. Nilai kekerasan tertinggi pada logam induk terjadi pada arus pengelasan 85 Amper dan terendah pada arus 80 Amper.

Grafik Daerah HAZ ( Heat Affected Zone ),memperlihatkan hasil uji kekerasan besi cor kelabu pada secara berurutan diperoleh nilai kekerasan daerah HAZ yaitu pada arus 80 ampere sebesar 195,24 VHN, pada arus 85 ampere sebesar 203,46 VHN dan pada arus 90 ampere sebesar 198,07 VHN. Nilai kekerasan tertinggi pada daerah HAZ terjadi pada arus pengelasan 85 ampere dan terendah pada arus 80 ampere.

Grafik pada daerah logam lasan ( weld metal ), memperlihatkan hasil uji kekerasan besi cor kelabu secara berurutan diperoleh nilai kekerasan logam lasan adalah pada arus 80 Amper sebesar 179,78 VHN, pada arus 85 Amper sebesar 200,68 VHN dan pada arus 90 Amper sebesar 211,18 VHN. Nilai kekerasan tertinggi pada daerah logam lasan terjadi pada arus pengelasan 90 ampere dan terendah pada arus 80 Amper.

\subsection{Pembahasan Uji Struktur Mikro}

Struktur matriks yang hampir sama yaitu grafit memanjang berukuran besar berwarna hitam, struktur ferit berwarna putih dan struktur perlit yang tampak berwarna kelabu dari ketiga variasi arus pengelasan, 
struktur mikro pada didaerah logam induk mempunyai. Struktur matrik yang hampir sama ini menghasilkan nilai kekerasan yang tidak terlalu jauh perbedaannya.

Pengamatan pada daerah HAZ dari ketiga variasi arus pengelasan yaitu, struktur mikro yang terbentuk juga mendekati sama, didominasi dengan martensit sehingga menyebabkan daerah HAZ menjadi keras dan mudah untuk terjadinya indikasi retak. HAZ mengalami temperatur yang tinggi karena dekat dengan daerah fusi, oleh karena itu pada temperatur tersebut, grafit flake mulai terlarut dalam austenite yang menghasilkan karbon dari grafit flake ke dalam austenite dan menghasilkan transformasi struktur. Kecepatan transformasi grafit ke austenite tergantung dari kecepatan difusi dari karbon. HAZ yang keras ini dapat terjadi karena dipengaruhi oleh faktor pendinginan yang masih terlalu cepat.

\section{Kesimpulan}

Hasil penelitian memberikan kesimpulan yaitu Nilai kekerasan maksimum terjadi pada spesimen dengan kuat arus pengelasan 90 ampere yang terdapat pada logam lasan (weld metal) yaitu sebesar 211,18 VHN, kemudian nilai kekerasan minimum terjadi pada spesimen dengan kuat arus pengelasan 80 ampere sebesar 179,78 VHN juga terdapat pada logam lasan. Sehingga dapat disimpulkan bahwa variasi kuat arus yang diterapkan pada proses pengelasan besi cor kelabu mengakibatkan adanya pengaruh terhadap kekerasan material.

Berdasarkan hasil pengamatan struktur metalografi dengan grafit berupa flake(serpih) pada logam induk berupa perlit. Struktur mikro pada daerah HAZ terbentuk struktur martensit. Sedangkan struktur mikro pada weld metal terdiri dari matriks austenite dengan persebaran partikel grafit yang merata.

Untuk saran perlu dilakukan penelitian lanjutan untuk menganalisis hubungan antara variasi pendinginan, variasi kampuh dan variasi posisi pengelasan.

Sebaiknya dilakukan pemanasan elektroda terlebih dahulu sebelum dilakukan proses pengelasan untuk menghilangkan hidrogen yang ada pada flux, karena hidrogen akan menyebabkan hasil lasan yang kurang baik.

\section{Daftar Pustaka}

[1] S. W. S. Subermono Subarmono, Rusiyanto Rusiyanto, "Pengaruh pemanasan paska pengelasan terhadap sifat mekanis besi tuang kelabu," J. Mesin dan Ind., vol. 4, pp. 89-95, 2017.

[2] A. N. S. Hd and S. Widodo, "PENINGKATAN SIFAT MEKANIS BESI COR KELABU MELALUI PROSES TEMPERING," vol. 2, no. 2, pp. 8-17, 2018.

[3] P. Smaw and B. Astm, "PENGARUH JENIS ELEKTRODA TERHADAP SIFAT MEKANIK HASIL PENGELASAN SMAW BAJA ASTM A36," vol. 13, no. 1, pp. 27-31, 2017.

[4] S. R. Schmid, Manufacturing Engineering and Technology. .

[5] M. Tiwan, "Analisis Sambungan Lasan Logam Besi Tuang Kelabu Dengan Menggunakan Las Oksi Asetilin.”

[6] A. links open overlay panelSumitMahajanWarisNawaz

KhanRahulChhibber, "CaO-CaF2-SiO2-Al2O3 system for development of SMAW electrodes with Ni alloy core wire," Ceram. Int. Available online 8 March 2021 Press. J. Pre-proofWhat are J. Preproof Artic., 2021.

[7] Y. Kchaou, N. Haddar, G. Hénaff, V. Pelosin, and K. Elleuch, "Microstructural, compositional and mechanical investigation of Shielded Metal Arc Welding ( SMAW ) welded superaustenitic UNS N08028 ( Alloy 28 ) stainless steel," J. Mater., vol. 63, pp. 278-285, 2014, doi: 10.1016/j.matdes.2014.06.014.

[8] G. M. Reddy and K. S. Rao, "Welding of nickel free high nitrogen stainless steel: Microstructure and mechanical properties," vol. 13, 2017, doi: 10.1016/j.dt.2016.06.003.

[9] G. Magudeeswaran, V. Balasubramanian, and G. M. Reddy, "Metallurgical characteristics of armour steel welded joints used for combat vehicle construction," Def. Technol., vol. 14, no. 5, pp. 590-606, 2018, doi: 10.1016/j.dt.2018.07.021.

[10] Q. Ahsan and U. Teknikal, $9 \%$ Nickel Steels and Their Welding Behavior, vol. 6. Elsevier, 2014. 